\title{
THE ROLE OF TIME IN PLACE ATTACHMENT CASE STUDY: JAVAHERDEH RECREATION AREA OF RAMSAR
}

\author{
Seyedeh Haniyeh Nejati \\ MA in Architecture \\ hnejati.design@gmail.com \\ Mohammad Mahdavi \\ Associate Professor at Islamic Azad University, Nour Branch
}

\begin{abstract}
Quantitative studies have shown that the duration of the relationship is considered an important variable in the development of place attachment. However, the study of place attachment and the meaning of this attachment do not provide us much information. The present study was conducted to explain the relationship between time and place attachment in two groups including travelers and natives who were presented in Javaherdeh region of Ramsar. The results showed that the duration of the relationship plays an important role in the process that connects people with place and finally, there are different ways in which the time is effective in the formation of meanings in a place.
\end{abstract}

Keywords: place attachment, time, Javaherdeh region of Ramsar

\section{INTRODUCTION}

Different concepts of attachment between people and places are presented and studied. Among the most common are concepts of place attachment and sense of place (SOP). What can be seen in the latest systematic studies regarding the attachment to a place is dealing with the importance of time in a place (that is, the duration of the relationship with a place). Since both authors and researchers (Lu and Altman, 1992; Moore and Graefe, 1994; Ralph, 1976; Tuan, 1977) believed that time and experience in a place are important factors in deepening the meanings and emotional ties needed in relationship between human and space, few depth investigations have studied these factors and their role in shaping this relationship. Therefore, this study attempts to provide a deeper understanding of the impact of "time variable" on the relationship between the visitors and local people at Javaherdeh region of Ramsar.

\section{CONCEPTS OF PLACE ATTACHMENT AND AN OVERVIEW OF THE THEORY OF TIME}

Place attachment, which is characterized by emotional ties with a place, generally derived from longterm relationship with a place. This issue different from the View that States that a place is special because of its beauty, which is often a simple aesthetical answer. For example, someone can describe the beauty (or ugliness) in a place, however, this response may sometimes be superficial and short. According to Schroeder (1991), this is a distinction is in which the "meaning" is in front of "trends". He described meaning as "thoughts, emotions, memories, and perceptions arising from the impact of a Landscape", and described the trend as "a tendency to a landscape in comparison with others". For a deeper emotional and sustainable attachment - or according to Schroeder, making sense for the attachment - a lasting relationship with a place is a very important factor. In general, the research describes two basic dimensions of attachment to a place, the place identity and place attachment. Place attachment taken from the framework defined Stokols and Schumacher (1981) and refers to the intensity of the relationship between a person and a place. Attachment to a place emphasizes on the practical aspects of the relationship between a person and a place: Does this attachment meet the practical needs of the person? The duration of relationship with a place and past experiences both are involved in creating and deepening attachment to a place. Stokols and Schumacher (1981) believed that maintaining and repeat are two very important characteristics in the relationship between a person 
and a place. Maintain a relationship refers to duration of the relationship with a place, while the repetition points out to the number of times a person is connected to a place. Thus, the relationship between humans and place has always a "time factor".

At first, the concept of place identity was developed by Proshansky and colleagues (1983) and then was modified by Korpela (1989). In his view, the place identity is the outcome of environmental compatibility in which the emotional attachment is at the heart of place identity. Thus, place identity refers to a more emotional dimension that will deepen over time and be established. Ralph (1976) and you have (1977) discussed the concept of time which are related to a place. The works of Homan (1992) concerning the attachment to social environment showed that long-term stay increases the feeling of attachment. This is achieved through familiarity, past experience, passage of time and native social relations. Studies regarding the recreation areas have shown that the time apparently plays a role in attachment to a place. Moore and Graefe (1994) investigated the attachment and dependence to a place and place identity in a quantitatively manner for the recreational areas. They observed that long relationship, continuous use and further proximity can increase the scales of attachment to a place. They observed differences in the formation of these attachments while taking a longer time to seek a more emotional place identity. Other studies have reported similar relationship between attachment to a place and duration of the relationship with a place.

\section{CHANGE IN MEANING OVER TIME}

A handful of studies have separated the importance of a place for a person from the extent of the person's attachment to the desired place and the meaning surrounding it. According to Stedman (2002), attachment to a place (as an intensity scale) is different from the meanings of place by which the attachment can be made. Since the attachment to a place is partially based on the meanings given to a place; according to him, these concepts should be separated. Some researchers have said that the place meanings may be influenced by the duration of the relationship with a place. For example, Kitayama and Markus (1994) believed that the feeling about a place may change over time, while the importance of different attributes in a place will change over time. They argued that newcomers may express that relationship with a region is based on environmental characteristics, while native people form a relationship based on social relations. This hypothesis is partially confirmed in research by Michel and colleagues (1993) about those present at Javaherdeh region of Ramsar. Cantill (1998) and Cantill and Seneca (2000) confirmed this hypothesis in a social environment in the State of Michigan. Interviewee who lived less than 15 years in this social environment, with describing this feeling to a place, discuss about the properties of nature / environment in that area, while residents who lived more than 15 years in the area referred to their social relations. This is reinforced by the findings of numerous studies about the social environment.

\section{RESEARCH GOAL}

A number of studies have shown that duration of the relationship with a place plays an important role in the attachment, but this did not evaluated profoundly (Kaltenborn, 1998, Moore and Graefe 1994, Peterson and Williams 1991, Verkin and Rice 2001). In this study, quantitative methods were used to confirm the role of time in the place attachment and qualitative methods were used to describe the basic process in the formation of place attachments and things associated with it.

\section{RESEARCH QUESTIONS}

Based on previous research, the key question of this study was that (1) whether people who have a longer relationship with a place (in Javaherdeh of Ramsar and other places) express emotional and social meanings when describing that place? On the other hand, do people who have a short-term relationship consider the physical activities and environments an important matter, when describing their relationships with that place? In other words, does the duration of the relationship with a place is related to the nature of the attachment in a person?

\section{PROCEDURES AREA OF STUDY}


Javaherdeh region of Ramsar is located in the northwest of Mazandaran province. As a recreation center, there are 150 thousand trips per year. Most visits are done in the summer (Dena information network, 2014). This area is a mountainous area and its famous recreations includes hiking, walking and other leisure that are done in an open natural environment. This place has an economy based on tourism revenue.

\section{DATA COLLECTION METHOD}

Data collection method was carried out through library and field research. In this case, theoretical and applied research through library research study and data collection related to population were obtained from the study.

\section{STATISTICAL SOCIETY}

The population consisted of people visiting the place of Javaherdeh (visitors for the first time and second time visitors) and native inhabitants Jewelry ten Ramsar (relative residents and residents of marriage), respectively. Due to the vast population and limited time, the inductive reasoning was used to identify the statistical population (samples and sampling) (Habibpour et al., 2012). Sampling in this study was done by simple randomization. Cochran formula was used to determine the sample size (Habibpour et al., 2012). In this study, the sample size was calculated as much as 732 persons. There are the most tourists in the months of July, August and September and the questionnaires were distributed among the statistical population during the mentioned period in 2014.

\section{DATA COLLECTION TOOLS}

In this study, the two methods of data collection were used: questionnaires and individual interviews. Likert scale was used to measure attitudes. In this research, the content validity was used to determine the validity (Tabibi, 2009) and Cronbach's alpha was used to determine the reliability (Habibpour et al., 2012). In this study, the standardized alpha was calculated 0.879 , which indicates that 30 items related to the attachment to a place have high internal reliability. The purpose of the questionnaire is collecting information about the duration of the relationship with Javaherdeh region of Ramsar. The questions focused on repetition and maintaining this relationship: (1) the duration of stay (in hours or days) in Javaherdeh, (2) the number of visits from Javaherdeh and (3) the number of years, the subjects visited Javaherdeh. This study collected information on specific places in Javaherdeh and other places. The visitors were asked to name the top three places in Javaherdeh and their reasons and determine how long they stay in each of the three places. This method was used to achieve deep meanings.

Individual interviews of Javaherdeh visitors (non-native) and permanent residents (native) was performed. The selection was based on key variables associated with place attachment. Random sampling was used to achieve a diverse number of visitors and based on the variables that affect the visitation from this recreation area. 9 separate interviews were done with Javaherdeh visitors during July, August and September 2014 in which 4 interviews were done with couple; in fact, one of each couple interviewed and totally, there were 13 participants. In addition, 29 interviews were conducted with the residents of Javaherdeh between July and August 2014. The key variable related to research is the duration of residence in this city and the number of years of residence amongst the interviewees varied from one and a half years to over 65 years. In total, 38 interview conducted from residents and visitors and 42 people attended. Interviews includes discussions on consequential or special places in Javaherdeh, and then the important and special places in another place. The key objective was to ensure that the interviewees use appropriate words with meanings to describe their relationship with the desired places. Interviews of visitors from Javaherdeh last 20 to 45 minutes (on average about half an hour) and from the residents of Javaherdeh last 30 to 60 minutes.

\section{THE RESULTS OF THE QUESTIONNAIRE}

A total of 649 questionnaires were distributed throughout the sampling at Javaherdeh region of Ramsar. Of these, 493 visitors filled out the questionnaires, which comprised a total of $76 \%$. The results of questionnaires and interviews provided and will be described in the following sections. First, differences in characteristics between visitors who have a special place in Javaherdeh and those 
who did not have such a place will be studied, whereas this study emphasizes on the duration of the relationship. Then, the differences in the meanings related to the duration of the relationship with a place will be examined. Finally, the results of interviews will be discussed based on the findings of the questionnaires.

\section{COMPARE PEOPLE WITH SPECIAL PLACES AND PEOPLE WITHOUT ANY SPECIAL PLACE BASED ON THE CHARACTERISTICS OF VISIT}

$48 \%$ visitors stated that some special places at Javaherdeh were important to them. The results of Table 1 shows that among those who had a special place and people who did not have a specific place, based on visitor characteristics, including repeated visits to people, maintain contact, and stay up and no statistically significant differences were observed. People who reported specific place showed a significant longer-term stay (3.4 days against 2.2 days, the result of t-test was equal to 3.134 ), they have more visitations to Javaherdeh (9.6 against 2.0 and t-test was equal to 6.352), had a longer relationship with Javaherdeh (16.1 years against 9.7 and t-test was equal to 4.317).

Table 1. Duration of familiarity and special places

\begin{tabular}{|l|l|l|c|}
\hline & $\begin{array}{l}\text { Has a special place } \\
\text { (Average) }\end{array}$ & $\begin{array}{l}\text { Without special place } \\
\text { (average) }\end{array}$ & t-statistics \\
\hline Length of stay (days) & 4.3 Day & 2.2 Day & $\mathrm{t}=3 / 134^{* *}$ \\
\hline number of visits & 6.9 visits & 2 Visits & $\mathrm{t}=6 / 352^{* *}$ \\
\hline $\begin{array}{l}\text { Duration of } \\
\text { familiarity (years) }\end{array}$ & 16.1 years & 9.7 years & $\mathrm{t}=4 / 317^{*}$ \\
\hline
\end{tabular}

* The amount of statistical difference, $\mathrm{p}<.01$

** The amount of significant difference, $\mathrm{p}<.001$

\section{REPEAT, STAY CONNECTED, AND SENSE OF PLACE}

The visitors expressed different meanings for a place and they were listed in Table 2. The most common meanings are: (1) physical environment, (2) outdoor recreational activities, (3) emotional ties, (4) watch the wild, (5) escape from loneliness, (6) social interaction, (7) Leisure, (8) pristine nature of Javaherdeh and (9) habit/ spending time.

Table 2. Repeat sense of place

\begin{tabular}{|l|c|c|}
\hline Sense of place & $\begin{array}{l}\text { The number of respondents } \\
\text { who use the meaning }\end{array}$ & $\begin{array}{l}\text { Percent of respondents with a } \\
\text { special place }\end{array}$ \\
\hline physical environment & 227 & 73 \\
\hline outdoor recreational activities & 165 & 53 \\
\hline emotional ties & 95 & 30 \\
\hline watch the wild & 92 & 30 \\
\hline escape from loneliness & 85 & 27 \\
\hline social interaction & 76 & 24 \\
\hline Leisure & 49 & 16 \\
\hline pristine nature & 31 & 10 \\
\hline habit / spending time & 26 & $8 / 3$ \\
\hline Accommodations / Food & 25 & 8 \\
\hline Boost morale & 16 & $5 / 1$ \\
\hline Culture and history & 15 & $4 / 8$ \\
\hline
\end{tabular}

\section{DURATION OF RELATIONSHIP AND MEANINGS OF PLACE}


Chi-square test results in Table 3 indicate statistically significant differences between the duration of familiarity for visitors and meanings of place. The visitors who have visited Javaherdeh several times, compared with the newcomers, have chosen the following meanings as important factors: Outdoor recreational activities, quiet spot, social attachments, special moments and ceremonies. There is no difference between the meanings of place in the physical environment and emotional connection with visitors of places.

Table 3. Significant differences between frequent visitors and newcomers

\begin{tabular}{|l|c|c|c|}
\hline Sense of place & $\begin{array}{l}\text { The percentage of } \\
\text { visitors who have visited } \\
\text { the place several times } \\
\text { and using the sense of } \\
\text { place }\end{array}$ & $\begin{array}{l}\text { The percentage of first } \\
\text { time visitors and using } \\
\text { the sense of place }\end{array}$ & $\begin{array}{l}\text { Chi-square } \\
\text { statistic }\end{array}$ \\
\hline Physical environment & $\% 71$ & $\% 77$ & $\mathrm{NS}$ \\
\hline $\begin{array}{l}\text { Outdoor recreational } \\
\text { activities }\end{array}$ & $\% 60$ & $\% 34$ & $\begin{array}{c}\mathrm{X}^{2}= \\
16 / 715^{*}\end{array}$ \\
\hline Emotional communication & $\% 32$ & $\% 27$ & $\mathrm{NS}$ \\
\hline Community Relations & $\% 29$ & $\% 12$ & $\mathrm{X}^{2}=9 / 521^{*}$ \\
\hline Special moments & $\% 19$ & $\% 07$ & $\mathrm{X}^{2}=6 / 267^{*}$ \\
\hline Quiet spot & $\% 15$ & $\% 5$ & $\mathrm{X}^{2}=5 / 832 *$ \\
\hline Time or customs & $\% 11$ & $\% 2 / 4$ & $\mathrm{X}^{2}=5 / 271^{*}$ \\
\hline
\end{tabular}

* The amount of significant difference, $\mathrm{p}<.01$

** The amount of significant difference, $\mathrm{p}<.001$

NS: absurdity

\section{THE DIFFERENCES BETWEEN THE MEANINGS OF PLACE AND TIME-RELATED} VARIABLES

The results of determining differences between the meanings of place and time-related variables are in Table 4. In connection with the number of visits, the meanings of place that are significantly associated with more visits, were included outdoor recreation and physical environment. Some of the meanings had greater importance in the view of those who visit Javaherdeh more frequently, and thus the strongest relationship with the Javaherdeh places were: outdoor recreation, social relations, special times, pastime or habit and amenities.

Table 4. The differences between the meanings of place and time-related variables

\begin{tabular}{|r|r|r|}
\hline \multicolumn{1}{|l|}{ time-related variables } & \multicolumn{1}{|l|}{ meanings of place } & \multicolumn{1}{|l|}{$\mathrm{t}$-statistics } \\
\hline \multirow{2}{*}{ Repeat } & Outdoor recreation & $\mathrm{t}=2 / 295^{*}$ \\
\cline { 2 - 3 } & Physical environment & $\mathrm{t}=3 / 434^{* *}$ \\
\hline Maintain contact & Outdoor recreation & $\mathrm{t}=3 / 117^{* *}$ \\
\cline { 2 - 3 } & Social relations & $\mathrm{t}=2 / 091^{*}$ \\
\cline { 2 - 3 } & special times & $\mathrm{t}=2 / 181^{*}$ \\
\cline { 2 - 3 } & Pastime or habit & $\mathrm{t}=1 / 984^{*}$ \\
\cline { 2 - 3 } & Amenities & \\
\hline
\end{tabular}


$*$ The amount of significant difference, $\mathrm{p}<.01$
$* *$ The amount of significant difference, $\mathrm{p}<.001$

\section{QUESTIONNAIRE}

These findings only partly confirmed previous research. Because the theory (Cantrill and Senecah 2000, Kitayama and Marcus 1994) and research (Gerson et al., 1977, Hummon, 1992, Lalli, 1992, Taylor et al., 1985) indicate that long relationship with a place can change the basis of attachment from physical aspects to social dimension. In previous investigations, frequent visitors (repetition variable) and those who come there for years (relationship variables), are associated with social relations inside Javaherdeh region of Ramsar. Because the emotional ties do not showed any difference between frequent visitors and newcomers, the frequent visitors probably reported the codes of "special times" and "escape from loneliness", which both of them have emotional characteristics.

Contrary to expectations, there is no difference between frequent visitors and newcomers on the reports related to the physical environment. That is common sense among all the visitors. In addition, those who had more visits (the repetition variable) reported further meanings associated with the environment. Interesting point is that the frequent visitors, more visits, and number of years were associated with more reports about outdoor recreation and it is a meaning that was thought to have a close relationship with the environment. A possible reason for this difference may be the kind of place that was investigated in this study. Most previous studies of this type were conducted based on the social environment, rather than entertainment venues. The physical environment is frequently mentioned by all visitors in that area, because Javaherdeh is a special place regardless of the duration of the relationship with a place. This area is a recreational area with scenic beauty, and is also a place where there is outdoor recreation. So, it's no wonder that most people, because of aesthetic values and recreational opportunities, often tend to travel to this area. These findings show the importance of the type of the site studied and its association with the development of different meanings. This relationship requires further study.

\section{THE RESULTS OF INTERVIEWS AND DISCUSSION}

Interviews with local residents

In the analysis of the interviews with the residents of Javaherdeh, any specified important place mentioned that the person has a proper "intensity" in his visits in terms of duration of the relationship with a place. The term "intensity" is the same concept of "experimental records" which was found by the Schreier et al (1984). Intensity suggests that a person visiting an area several times, and is looking to repeat and maintain contact with a place. When the interviewee refers to a place, the intensity of that place should be changed and be gained a low, medium and high score. For example, examples of low intensity is a person who visited a place five times over 30 years, or twice during the five years, while the examples of high intensity is a person who visited a place 50 times over 25 years or 10 times over two years. Similarly, places outside Javaherdeh region are those that local respondents strongly associated at least in a medium average.

\section{INTERVIEW WITH NON-NATIVE PEOPLE}

The interviews with non-native people revealed the role of time in the sense of space. 8 out of 13 respondents describe a special place Javaherdeh, while the other five did not report any specific place. In reviewing the intensity of relationship with Javaherdeh, the intensity among the non-native visitors is much different than the local people. This was expected, because non-native interviewees primarily considers Javaherdeh as a recreational area and so they do not spend a lot of time here, compared with the native people. In terms of intensity associated with Javaherdeh, the intensity of one of eight visitors who had an important place was high, one of them has already a high, but now it has been extremely low; two persons have medium intensity; and 4 persons have a low intensity. And for 5 visitor who did not report an important place, the intensity of the relationship was different: namely, 2 person have high intensity, one person has medium intensity and two persons have low intensity. However, when they were asked to mention an important place outside the Javaherdeh, all but one 
interviewee spoke comfortably about a place, and 4 out of 13 persons described their homes or a place where they lived, while they explained the importance of the home environment. The rest of the interviewees talked about the entertainment places which had visited them several times and it was found that there is a mild connection between them and those places.

\section{TALK ABOUT THE INTERVIEWS AND MEANINGS OF PLACE}

Moore and Graefe (1994) thought that the ways in which different types of attachments to place, are formed can be different. Attachment to a place was created apparently too fast, while the identity of the places needs more time. Similarly, other researchers (Cantill and Senecah, 2000, Kitayama and Marcus 1994) thought that the social relationship will be more prominent and important over time; while at first, often associated with physical characteristics that are important. These hypotheses in the results of the analysis of the interviews were confirmed. A distinction created by some of the interviewees was that their feelings have changed about the place by gaining experience and with the passage of time. They pointed out their reasons for their first visit to Javaherdeh or visit the places of Javaherdeh and they said that when they lived in this area or have spent more time there, the area has changed or grown. It seemed that they distinguished between the "orientation" and "meaning." And this difference has focused on one of the two words "attractiveness" in front of "attachment" in the next section.

\section{ATTRACTIVENESS FOR THE ATTACHMENT}

Some of the interviewees described how assimilation into specific places or relationship with them in Javaherdeh and outside of it. Many of them have confirmed this relationship with the place. In total, there are differences in the basic meanings and stable attachment. They often say that the beauty of the physical environment was what first drew their attention. However, this attractiveness was entirely different meanings and emotional attachments that were formed in the life and the long attachment leads to emotional and social relations with that place which was more significant. Being in a place, spend time there and gain the experience is very important in terms of emotional and social. These examples confirmed previous research and assumptions which argue that with the passage of time, the relationship between people and place will be more profound and social and emotional aspects can be formed. (Cantrill and Senecah 2000, Kitayama and Marcus 1994, Moore and Graefe 1994).

\section{CONCLUSION}

The importance of time in establishing a relationship between people and places in this study was proven. The results of the questionnaires confirmed the past findings and assumptions, which considered the duration of the relationship with a place an important factor in creating attachment to a place. Compared with the newcomers, the persons who had visited Javaherdeh many times, reported a place which was important and meaningful for them. The questionnaire findings also showed that the duration of the relationship with a place affects the meanings of place attachment. About the interviewees, an important difference was that their feelings about a places has changed during the time and because of their experience in that place. This aspect of the relationship between person and place in the research called the "attractiveness" for "attachment". Other researchers (Cantrill and Senecag, 2000, Kitayama and Marcus 1994, Moore and Graefe 1994, Schroeder 1991) argued that this type of meanings be changed over time and believed that a variety of place attachment be created in different forms. Over time, unlike the early stages of a person's relationship with places, more social and emotional relationships with places seem to be more prominent, while physical environments are often very important. According to this interpretation, this framework shows that the relationship between the humans and place has its roots in the constantly changing time scale which provides the critical situation affecting this relationship.

\section{REFERENCES}

Habibpour, K., and Safari, R. (2012). A comprehensive guide for the application of SPSS in survey research, Motefakkeran publications 
Dena Information network, 2014. The 55 percent growth in foreign tourists visit from the Palace Museum in Ramsar. www.dana.ir/news/249687.hpml

Tabibi, J. et al. (2009). Dissertation development, essay, research projects and scientific papers, Ferdos Publication

Brandenburg, A.M.; Carroll, M.S. 1995. Your place or mine? : The effect of place creation on environmental Values and Landscape Meanings. Society and Natural Resources. 8: 318-398. Cantrill,J. 1998. The Environmental Self and a sense of place: communication foundations for regional ecosystem management. Journal of Applied Communication. 26: 301-318. Cantill, J.; Senecah, S. 2000. A "Sense of Place" for the Environmental Self in Conservation Psychology. Paper presented at the $8^{\text {th }}$ International Symposium on Society and Resource Management, Western Washington University, Bellingham, WA.

Case, D. 1996. Contributions on journeys away to the definition of home: An empirical study of a dialectical process. Journal of Environmental psychology. 16: 1-15.

Gerson, K.; Stueve, C.; Fischer, C. 1977. Place attachment. In C. Fischer, ed. Network and Places. NY: The Free Press.

Gunter, B. 2000. Psychology of the Home. Philadelphia, PA: Whurr Publications, Ltd. Hay, R. 1998. Sense of place in developmental context. Journal of Environmental Psychology. 18: 529.

Hummon, D.M. 1992. Community Attachment: Local Sentiment And Sense Of Place. In I. Altman; Low, S.M., eds. Place Attachment (pp. 253-278). NY: Plenum Press.

Kaltenborn, B. 1997. Nature of place attachment: A study among recreation homeowners in Southern Norway. Leisure Sciences. 19: 175-189.

Kaltenborn, B. 1995. Effects of sense of place on responses to environmental impacts. Applied Geography. 18(2): 169-189.

Kitayama, S.; Markus, H.R. 1994. Culture and self: How cultures influence the way we view ourselves. In D. Matsumoto, ed. People: Psychology from a cultural perspective (pp. 17-37). .Pacific Grove, CA: Brooks/Cole.

Korpela, K. 1998. Place-identity as a product of environmental self-regulation. Journal of Environmental psychology. 9: 241-256.

Lalli, M. 1992. Urban-related identity: theory, measurement, and empirical findings. Journal of Environmental Psychology. 12: 285-303.

Low, S.M.; Altman, I 1992. Place Attachment: A Conceptual Inquiry. In I. Altman; Low, S.M. eds. Place Attachment (pp. 1-12). NY: Plenum Press.

Mailes, M.; Huberman, A.M. 1994. Qualitative Data Analysis. Thousand Oaks, CA: Sage Publications, Inc.

Mitchell, M.Y.; Force, J.E.; Carroll, M.S.; McLaughlin, W.J. 1993. Forest place of the heart: incorporating special spaces into public management. Journal of Forestry. 4: 32-37.

Moore, R.; Graefe, A. 1994. Attachments to recreation settings: The case of rail-trail users. Leisure Sciences. 16: 17-31.

Patterson, M.E.; Williams, D.R. 1991. A transactional approach to characterize relationship to resource. Paper presented at the NRPA Symposium; 1991, Oct. 19; Baltimore, MD.

Pattin, M.1990. Qualitative Evaluation and Research Methods. Newbury Park, CA: Sage Publications, Inc.

Proshansky, H.M.; Fabian,; Kaminoff, r. 1983. Place-identity: Physical world socialization of the self. Journal of Environmental psychology. 3: 57-83.

Qualitative Solutions and Research. 1999. QSR*NUDIST Vivo 1.0. Pty. Ltd, Victoria, Australia.

Relph, Edward. 1976. Place and Placelessness. London: Pion Limited.

Riley, R.B. 1992. Attachment to the ordinary landscape. In I. Altman; Low, S.M., eds. Place

Attachment (pp. 13-36). NY: Plenum Press.

Salant, P.; Dillman, D.A. 1994. How to conduct your own survey. New York, NY: John Wily \& Sons. Schroeder, H. 1991. Preference and meaning of arboretum landscapes: Combining quantitative and qualitative data. Journal of Environmental psychology. 11: 231-48.

Schreyer, R.; Lime, D.; Williams, D. 1984. Characterizing the influence of past experience on recreation behavior. Journal of Leisure Research. 16: 34-50.

Shamai, S. 1991. Sense of place: an empirical measurement. Geoforum. 22 (3): 347-358. 
Smaldone, D.; Harris, C.C.; Sanyal, N.; Lind, D. 2005. Place attachment and management of critical park issues in Grand Teton National Park. Journal of Park and Recreation Administration. 23(1): 90114.

Stedman, R. C. 2002. Toward a social psychology of place: predicting behavior from place-based cognitions, attitude, and identity. Environment and Behavior. 34(5): 561-581.

Steele, F. 1981. The sense of place. Boston: CBI.

Stokols, D.; Schumaker, S.A. 1981. People in places: A transactional view of settings. In J. Harvey, ed. Cognition, Social behavior and the Environment. NJ: Erlbaum.

Tuan, Y. 1974. Topophilia: A study of environmental perception, attitudes and values. Englewood Cliffs, NJ: Prentice-Hall. 